\title{
A new scoring system for placement of abdominal aortic balloon in Placenta accreta spectrum patients with placenta previa: A retrospective cohort study
}

\section{Fusen Huang ( $\sim 793736612 @ q q . c o m)$}

Chongqing University of Medical Science: Chongqing Medical University https://orcid.org/0000-0002-3995-8991

\section{Jingjie Wang}

Chongqing University of Medical Science: Chongqing Medical University

\section{Qiuju Xiong}

Chongqing University of Medical Science: Chongqing Medical University

\section{Wenjian Wang}

Chongqing University of Medical Science: Chongqing Medical University

\section{Yi Xu}

Chongqing University of Medical Science: Chongqing Medical University

Jia Zhuo

Chongqing University of Medical Science: Chongqing Medical University

\section{Qiuling Xia}

Chongqing University of Medical Science: Chongqing Medical University

Xiaonan Liu

Chongqing University of Medical Science: Chongqing Medical University

\section{Research Article}

Keywords: scoring system, cesarean section, aortic balloon occlusion, Placenta accreta spectrum, placenta previa

Posted Date: September 14th, 2021

DOI: https://doi.org/10.21203/rs.3.rs-898065/v1

License: (c) (i) This work is licensed under a Creative Commons Attribution 4.0 International License. Read Full License 


\section{Abstract \\ Background}

In recent years, abdominal aortic balloon occlusion is considered an effective method for placenta accreta spectrum patients with placenta previa. However, not all patients in this category require abdominal aortic balloon placement.

This study aims to investigate whether the new scoring system is effective for the placement of the abdominal aortic balloon in Placenta accreta spectrum (PAS)patients with placenta previa.

\section{Methods}

PAS patients with placenta previa diagnosed by color Doppler ultrasound were included, and divided into three groups according to their scores graded by a new scoring system (grade $₫$ group $\leq 5$ points, 6 points $\leq$ grade $\llbracket$ group $\leq 9$ points, grade $\varangle$ group $\geq 10$ points). Patients with grade $\varangle$ were placed with an abdominal aortic balloon unless their families and patients strongly refused. Those with grade I were not placed with an abdominal aortic balloon. Those with grade II generally were not placed with an abdominal aortic balloon unless their families and patients strongly request. Indicators were analyzed, including postpartum hemorrhage, transfusion requirements, operation time, and the ability to preserve the uterus and fertility.

\section{Results}

Estimated blood loss, the number of intraoperative transfused patients, postoperative days were different among the three groups. In group 2 (grade II), there was no significant difference in other observation indexes $\operatorname{lintraoperative}$ blood loss $629 \pm 214$ vs $758 \pm 749, P=0.488$, packed red blood cells $47 \pm 194$ vs $154 \pm 445, P=0.488$, admission to ICU $0 / 7$ vs $3 / 71, P=1.000$, total hysterectomies $0 / 7$ vs $2 / 71, P=1.000$ (except for the operation time $81.4 \pm 19.5$ vs $61.7 \pm 30.6, P=0.013$ ) between the abdominal aortic balloon and non-abdominal aortic balloon groups. In group 3 (grade III), significant differences were found in intraoperative blood loss ( $950 \pm 390$ vs $2238 \pm 1052, P \llbracket 0.001$ ), packed red blood cells $(213 \pm 311$ vs $662 \pm 528, P \llbracket 0.001)$, postoperative blood transfusion volume( $105 \pm 181$ vs $300 \pm$ $321, P=0.008)$, operation time $(90.0 \pm 25.9$ vs $115.9 \pm 45.3, P=0.013)$, the proportion of people who need blood transfusion ( 14 in the IABO vs 11 in the NIABO, $P=0.002)$ and the total Hysterectomies ( 0 in the IABO vs 2 in the NIABO, $P=0.011)$ between the abdominal aortic balloon and non-abdominal aortic balloon groups.

\section{Conclusion}

With the new scoring system, not all patients with PAS and placenta previa need a preventive temporary balloon occlusion of the subrenal abdominal aorta. We recommend placing an abdominal aortic balloon in patients with grade III, for it can control intraoperative bleeding and reduce intraoperative blood transfusion, and reduce the risk of hysterectomy. For patients with grade I and II, abdominal aortic balloon placement is not recommended.

\section{Background}

Placenta previa refers to the situation where the placenta is located in the lower part of the uterus, and the placenta partially or completely covers the internal cervix. Placenta accreta spectrum (PAS) is a general term used to describe abnormal trophoblast invasion into the myometrium of the uterine wall.[1, 2] The placenta that cannot be peeled off 
immediately after delivery would be peeled manually, which may cause hemorrhage and hysterectomy, leading to potentially life-threatening situations.[3, 4] With the release of China's second-child policy, more and more patients undergo a second cesarean section. However, the risk of placenta previa in subsequent pregnancies after cesarean section increases and is reported as 1.5-6 times that of vaginal delivery. The incidence of PAS has also increased. PAS coexisted with placenta previa is prone to developing life-threatening hemorrhage during surgery, which is a challenge for anesthesiologists and obstetricians; it can also lead to other related complications such as hysterectomy and even maternal and infant death.

Balloon occlusion is considered a possible effective method for avoiding and reducing complications.[5] In recent years, balloon occlusion of the abdominal aorta has been adopted due to its relatively simple operation, lower requirements for the operator and less radiation exposure. But there are still some controversies. Some researchers believe that the abdominal aortic balloon can achieve satisfactory hemostasis due to the higher position of the blockade; $[6,7]$ these studies only exist in some retrospective, small-sample studies. Currently, few randomized controlled studies were carried out for the general three reasons. Firstly, not all patients with PAS and placenta previa need to be placed with an abdominal aortic balloon[8]. Secondly, how to choose an appropriate patient for abdominal aortic balloon placement is not clear. Finally, the cost of installing the abdominal aortic balloon is relatively high and with some complications, such as abdominal aortic rupture, thrombosis, and arterial embolism.

Therefore, a new scoring system for grading the degree of placental implantation by transabdominal or transvaginal ultrasound is widely used in China and has been introduced in July 2019 in our hospital.[9] The reliability of ultrasound scoring to determine whether a subrenal abdominal aortic balloon placement is needed is unknown. This study retrospectively evaluated the clinical efficacy and necessity of the abdominal aortic balloon in PAS patients with placenta previa.

\section{Patients And Methods}

This study was approved by the Ethics Committee of the First Affiliated Hospital of Chongqing Medical University (registration number: 2021-059). We retrospectively analyzed the clinical data of PAS patients with placenta previa who underwent cesarean section from July 2019 to December 2020. The inclusion criteria were PAS patients with placenta previa diagnosed by color Doppler ultrasound and without other obstetric diseases. A total of 148 patients were divided into three groups according to their ultrasound score; group 1, less than 5 points (grade I); group 2, 6-9 points (grade II), and group 3, above 10 points (grade III). The degree of placenta accreta was graded by a new scoring system, as shown in Table 1 (total score is 18 points, grade $\varangle \leq 5$ points, 6 points $\leq$ grade $\nabla \leq 9$ points, grade $\bigotimes \geq 10$ points). The scoring system was established by Chong $Y$ et al., and our hospital introduced this system for reference. [9] Scores were weighted according to the following observation indicators, including position of the placenta, thickness of the placenta, continuity of the clear space, bladder line, lacuna, condition of the subplacental vascularity, blood sinus of cervix, morphology of cervix and history of cesarean section. Patients with grade $\nabla$ were required to place an abdominal aortic balloon unless their families and patients strongly refused; with grade I were not placed with an abdominal aortic balloon; with grade II were generally not placed with an abdominal aortic balloon

unless their families and patients strongly request. In addition, patients with an abdominal aortic balloon placed were included in the study group, and those without a balloon were included in the control group. In a further study, we compared the difference of the observation indicators in patients with and without balloons between group 2 and 3 . Important observation indicators were compared between group 2 and 3 . Considering the greater risk of bleeding, all patients with a balloon need to be inflated before the placenta is removed. The duration of inflation is determined by the bleeding situation. 


\section{Treatment methods}

After the fetus is delivered, 20 units of oxytocin were injected into the myometrium. If the placenta could not be peeled off automatically, it would be peeled off manually. If the placenta invaded up to one-third of the myometrial layer, we excised a section of the placenta, simultaneously ligated the bleeding vessels, and applied a $\infty$-shaped suture to the placental bed. After separating the placenta, we examined the placental bed and the depth of myometrial invasion. Conservative treatments were used in placenta accreta, including oversewing the placental bed, uterine tamponade, and bilateral uterine artery ligation. A hysterectomy was performed when the bleeding could not be controlled.

In the digital subtraction angiography (DSA) operating room, the abdominal aortic balloon was placed before the cesarean section. After local anesthesia, the balloon catheter was inserted into the abdominal aorta through the right femoral artery using the Seldinger puncture technique. With the help of the contrast agent, the catheter was located under the renal artery. Choose an appropriate size cuff, filled the cuff with the contrast agent, and recorded the dose of the contrast agent. The puncture site was bandaged and precisely marked. The catheter was fixed and filled with heparin solution for anticoagulation and standby application. After the balloon placement was complete, the patient was sent to the operating room for the cesarean section. The same dosage (the injected contrast agent) of normal saline (NS) was injected to fill the balloon for blocking the blood supply. If there was no obvious bleeding, the balloon was released to restore blood supply; if there was heavy bleeding, the balloon was inflated to block the abdominal aorta with the same specific hemostatic measures as before. If the bleeding could not be controlled, a hysterectomy was performed. The abdominal aortic balloon could be blocked intermittently during the operation to determine the hemostatic effect. To reduce related complications (severe thrombotic and embolic complications as reported), the cuff and sheath were removed immediately after surgery and the puncture point was compressed. Foot temperature, dorsal artery pulse, urination, and intestinal exhaust were closely monitored.

\section{Clinical characteristics}

Observed indicators include: intraoperative blood loss, blood loss within 24 hours after surgery, red blood cell infusion, blood transfusion rate, hysterectomy incidence, hospitalization time, transfer to ICU rate, and neonatal Apgar score.

\section{Statistical analysis}

All statistical analyses were conducted using the SPSS 22.0 software (IBM, Armonk, NY, USA). The categorical data were expressed as number/proportion and analyzed by $\mathrm{X}^{2}$-test. The continuous variables were expressed as mean \pm SD and analyzed by t-test. $\mathrm{P}<0.05$ was considered statistically significant. One-way analysis of variance, one-way analysis of variance Post hoc analysis of LSD, and chi-square test were used to compare continuous variables and categorical variables among the three groups, respectively

\section{Results}

There were 167 patients with PAS disorders proved by the intraoperative finding from Dec 2019 to Oct 2020in our hospital. A total of 148 PAS patients with placenta previa were included in the study, except for 19 patients without placenta previa, as shown in Figure 1. In group 1, 17 patients were placed with balloons, and in the third group, 13 patients refused to be ballooned. 
Gestational age (weeks), prior cesarean, and the scores were significantly different among the three groups(shown in table 2). Patients with grade III had a relatively smaller gestational week and a higher number of previous cesarean sections.

Maternal and neonatal outcomes are shown in Table 3. A significant difference was noted in estimated blood loss among the three groups (group 1: $514 \pm 212$ vs group 2: $695 \pm 585$ vs group 3: $1266 \pm 826, P \varangle 0.001$, Table 3 ). The number of intraoperative transfused patients was different among the three groups (group 1: 1; group 2: 14; group 3:

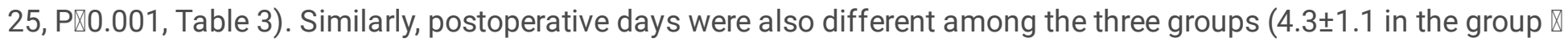

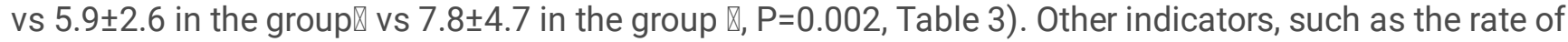
hysterectomy and ICU transfer, were not statistically different among the groups.

In group 2, no significant difference was observed in other observation indexes(except for the operation time) between the abdominal aortic balloon and non-abdominal aortic balloon groups (Table 4). In group 3 , significant differences were observed in intraoperative blood loss $(950 \pm 390$ in the IABO group vs $2238 \pm 1052$ in the NIABO group, $P \unrhd 0.001$, Table 4), packed red blood cells(213 \pm 311 in the IABO vs $662 \pm 528$ in the NIABO, P $\llbracket 0.001$, Table 4), postoperative blood transfusion volume(105 \pm 181 in the IABO vs $300 \pm 321$ in the NIABO, $P=0.008$, Table 4), operation time $(90.0 \pm 26.0$ in the IABO vs $115.9 \pm 45.3$ in the NIABO, $P=0.013$, Table 4), the proportion of people who need blood transfusion(14 in the IABO vs 11 in the NIABO, $P=0.002$, Table 4) and the total Hysterectomies ( 0 in the IABO vs 2 in the NIABO, $\mathrm{P}=0.011$, Table 4) between the abdominal aortic balloon and non-abdominal aortic balloon groups.

By the time of discharge, there were no maternal or fetal deaths in all groups, and all mothers and babies were healthy at discharge. Hematoma, rupture of the abdominal aorta, arterial embolism or thrombosis of lower extremities, acute renal failure and other related complications were not found.

\section{Discussion}

In China, with the implementation of the second-child policy, the incidence of second cesarean section has also increased. One of the most serious complications of PAS combined with placenta previa is postpartum hemorrhage that threatens the mother's life.[10] Compared with uterine atony, postpartum hemorrhage caused by PAS coexisting with placenta previa is more severe[11]. Current hemostasis measures include uterine artery embolization and uterine artery ligation. In this case, more and more researchers believe that balloon occlusion of the abdominal aorta can play a role,[5] but there are still some controversies.[12] Some researchers believe that not all PAS combined with placenta previa require abdominal aortic balloon placement $[8,13]$. Because the abdominal aortic balloon placement is invasive, there may also be some potential complications such as abdominal aortic rupture, thrombosis, acute renal failure, etc. $[14,15]$ At the same time, it may have certain effects on blood pressure, heart rate and internal environment. [16] What's worse, the mother and fetus can be exposed to radiation during balloon displacement. Therefore, the judicious use of these technologies is still advised, though the threshold for clinical sequelae is relatively low. $[16,17]$ Therefore, it is necessary to select suitable patients for abdominal aortic balloon placement.

Early diagnosis and prevention may reduce balloon placement-related complications. Because of ultrasound convenience, more and more obstetricians choose ultrasound to assess the severity of placenta previa. Due to the limitation of ultrasound in diagnosing PAS $[18,19]$, the severity of placental accreta may not be accurately predicted with ultrasound results. For the detection of placenta accreta, the ultrasound has been shown to have a sensitivity of 0.77 and specificity of 0.96 .[20] Therefore, we used a new scoring system combined with clinical characteristics and ultrasound features, which is widely used in China to guide the placement of the abdominal aortic balloon, which is different from the proposal for standardized ultrasound descriptors of the abnormally invasive placenta. [21] Table 3 
shows that with the increase of scores, there was increases in inestimated blood loss trasnfused patients, packed red blood cells, postoperative estimated blood loss, postoperative transfused patients,operation time,postoperative days. In the lower-scoring (grade I) group, in which the abdominal aortic balloon occlusion was not performed, we discovered no need for hysterectomy, massive blood loss, blood transfusion, or transfer to ICU, indicating that patients with lower scores do not need to have an abdominal aortic balloon. In the higher-scoring (grade III) group, most patients underwent subrenal abdominal aortic balloon placement. In the highest-scoring group, two patients(3.77\%) underwent a hysterectomy, and one (1.89\%) was transferred to ICU, which is lower than those of Panici and Angstmann[20, 22] and higher than those of Wang and Li.[6, 23] These studies have proved that the abdominal aorta balloon occlusion can effectively reduce the probability of hysterectomy and postpartum hemorrhage, and futher illustrates that placement of the balloon can reduce the complications. The observation indicators of blood loss $(950 \pm 38 \mathrm{ml})$, blood transfusion $(213 \pm 311 \mathrm{ml})$ and the number of blood transfusions(35.0\%) in group3, were similar to previous studies.[20, 23, 24] These results show that balloon occlusion of the abdominal aorta may reduce the need for blood transfusion and the number of people transfused. In group 2, the rates of hysterectomy and ICU transfer were $2.27 \%$ and $3.41 \%$, respectively, which was not significantly different from group 3 ; the blood loss was $695 \pm 585$ and the blood transfusion rate was $15.91 \%$, which was lower than the group 3 , and both were lower than previous studies. $[20,24]$ The results show that most patients in group 2 did not use balloon occlusion, and their hysterectomy rate and ICU transfer rate were relatively low. The reason is mainly related to the relatively low scores of patients in the second group, which means that patients in group 2 may not need to be placed with an abdominal aortic balloon.However, there are still patients who underwent hysterectomy and were transferred to ICU. None of these patients happened to have an abdominal aortic balloon, further showing that the placement of the abdominal aortic balloon may reduce the rate of hysterectomy and ICU transfer. In addition, as the grouping level increases, the amount of bleeding, blood transfusion, and blood transfusion rate relatively increased even with the placement of a balloon. It is suggested that balloon occlusion of the abdominal aorta is only one of the factors affecting bleeding. [25]

Further studies have shown that using balloon blockade has different effects on the outcome in different groups. In grade II group, there was no significant difference between the abdominal aortic balloon and non-abdominal aortic balloon groups in the main observation indicators except for the operation time (Table 4). The incidence of blood loss, blood transfusion, hysterectomy, transfer to ICU, etc., is lower in group 2 than in previous studies.[7, 20, 26] The results show that patients with lower scores will not experience severe blood loss and do not require large amounts of blood transfusion even if the abdominal aortic balloon is not installed using a scoring system. It demonstrates that the use of abdominal aortic balloon occlusion is not necessary for grade Il group. At the same time, in the balloon placement group, the operation time was not shortened, which is different from Li's study. [24] It shows that in this group, the placement of the abdominal aortic balloon did not shorten the operation time. However, in the third group, the situation was completely different. The intraoperative blood loss, packed red blood cells, postoperative blood transfusion volume, the proportion of people who need blood transfusion and the total hysterectomies were different in patients with and without balloons. These observations have been significantly improved in patients with balloon placement, indicating the necessity of abdominal aortic balloon occlusion for the third group.

The main complications with balloon occlusion of infrarenal abdominal aorta are distal ischemia, reperfusion injury, thrombosis, and embolization of the lower extremities. Dilauro et al. reported that $5 \%$ of patients were at risk of thrombosis after the IIABO.[27] In this study, the balloon inflation time in all the patients was less than 30 min, and no complications were detected after the operation. By shortening the balloon inflation time and pulling out the balloon immediately after surgery, related complications may be effectively avoided. The early removal of the abdominal aortic balloon after cesarean section may reduce the incidence of postoperative thrombosis-related complications. 
The advantage of this study is that our hospital is one of the treatment centers for critically ill pregnant women in western China and has a standardized process for the management of PAS patients. All cases are enrolled in a year, and the continuous development of surgical expertise has little influence on its main results. The disadvantage of this study is the relatively small sample size as a retrospective study, which may be a selection bias. At the same time, we only follow up until the patient is discharged, which is relatively short. There may be some potential complications that have not been observed. In addition, this is a new scoring system that requires more researches to demonstrate its reliability. Although studies have shown the accuracy of the new scoring system for predicting the pathological type of placenta accrete of 83.9-92\%[9], there are still few related studies on this scoring system. This scoring system is relatively simple and commonly used in China, but not globally. However, this scoring system is different from Collins's proposal for standardized ultrasound descriptors of the abnormally invasive placenta. [21] The basis for this scoring system to guide grouping is not sufficient, but it generally reduces the placement rate of the abdominal aortic balloon.

In conclusion, with the use of the scoring system, not all patients with PAS and placenta previa need a preventive temporary balloon occlusion of the subrenal abdominal aorta. We need to recommend abdominal aortic balloon placement for patients with grade III, for it can control intraoperative bleeding and reduce intraoperative blood transfusion and the risk of hysterectomy. There is no need to perform abdominal aortic balloon placement for patients rated grade I and II. It is appropriate to use this scoring system to guide the placement of the abdominal aortic balloon.

\section{Declarations}

- Ethics approval and consent to participate

Ethical approval was sought from the Ethics Committee of the First Affiliated Hospital of Chongqing Medical University (registration number: 2021-059)\All methods were performed in accordance with the Declaration of Helsinki. The Ethics Committee of the First Affiliated Hospital of Chongqing Medical University informed that they waived the need for consent. For the medical records used in this study were obtained from previous diagnosis and treatment. The exemption of informed consent will not adversely affect the rights and health of subjects. The subjects' privacy and personal identity are protected.

- Consent for publication

Not applicable

- Availability of data and materials

The datasets used and/or analysed during the current study available from the corresponding author on reasonable request.

- Competing interests

None of the authors have any competing interests.

- Funding

The authors have no support or funding to report for the present study. 
- Authors' contributions

$\mathrm{FH}$ : participated in the design of the study, collected the data and conducted the analysis and drafted the manuscript. XL: designed the study and drafted the manuscript. JZ, WW, YX, JW and QL: collected the data. JW and QJ: carried out data analysis. All authors read and approved the final manuscript.

- Acknowledgements

Not applicable

- Authors' information (optional)

\section{References}

1. Jauniaux E, Ayres-de-Campos D: FIGO consensus guidelines on placenta accreta spectrum disorders: Introduction. International journal of gynaecology and obstetrics: the official organ of the International Federation of Gynaecology and Obstetrics 2018, 140:261-264.

2. Jauniaux E, Silver RM, Matsubara S: The new world of placenta accreta spectrum disorders. International journal of gynaecology and obstetrics: the official organ of the International Federation of Gynaecology and Obstetrics 2018, 140:259-260.

3. Angstmann T, Gard G, Harrington T, Ward E, Thomson A, Giles W: Surgical management of placenta accreta: a cohort series and suggested approach. American journal of obstetrics and gynecology 2010, 202:38.e1-9.

4. Machado LSM: Emergency peripartum hysterectomy: Incidence, indications, risk factors and outcome. North American journal of medical sciences 2011, 3:358-361.

5. Chen L, Wang X, Wang H, Li Q, Shan N, Qi H: Clinical evaluation of prophylactic abdominal aortic balloon occlusion in patients with placenta accreta: a systematic review and meta-analysis. BMC pregnancy and childbirth 2019, 19:30.

6. Wang Y-L, Duan X-H, Han X-W, Wang L, Zhao X-L, Chen Z-M, Chu Q-J, Zhang W: Comparison of temporary abdominal aortic occlusion with internal iliac artery occlusion for patients with placenta accreta - a non-randomised prospective study. VASA. Zeitschrift fur Gefasskrankheiten 2017, 46:53-57.

7. Wu Q, Liu Z, Zhao X, Liu C, Wang Y, Chu Q, Wang X, Chen Z: Outcome of Pregnancies After Balloon Occlusion of the Infrarenal Abdominal Aorta During Caesarean in 230 Patients With Placenta Praevia Accreta. Cardiovascular and interventional radiology 2016, 39:1573-1579.

8. Matsubara S: Letter to 'Intermittent aortic balloon occlusion combined with cesarean section for the treatment of patients with placenta previa complicated by placenta accreta: A retrospective study': Some concerns. The journal of obstetrics and gynaecology research 2019, 45:240-241.

9. Chong $\mathrm{Y}$, Zhang A, Wang $\mathrm{Y}$, Chen $\mathrm{Y}$, Zhao Y: An ultrasonic scoring system to predict the prognosis of placenta accreta: A prospective cohort study. Medicine 2018, 97:e12111.

10. Evensen A, Anderson JM, Fontaine P: Postpartum Hemorrhage: Prevention and Treatment. American family physician 2017, 95:442-449. 
11. Woiski MD, Scheepers HC, Liefers J, Lance M, Middeldorp JM, Lotgering FK, Grol RP, Hermens RP: Guidelinebased development of quality indicators for prevention and management of postpartum hemorrhage. Acta obstetricia et gynecologica Scandinavica 2015, 94:1118-1127.

12. Masamoto H, Uehara H, Gibo M, Okubo E, Sakumoto K, Aoki Y: Elective use of aortic balloon occlusion in cesarean hysterectomy for placenta previa percreta. Gynecologic and obstetric investigation 2009, 67:92-95.

13. Papillon-Smith J, Hobson S, Allen L, Kingdom J, Windrim R, Murji A: Prophylactic internal iliac artery ligation versus balloon occlusion for placenta accreta spectrum disorders: A retrospective cohort study. International journal of gynaecology and obstetrics: the official organ of the International Federation of Gynaecology and Obstetrics 2020, 151:91-96.

14. Sun W, Duan S, Xin G, Xiao J, Hong F, Hong H, Wu Y, Xu Y: Safety and efficacy of preoperative abdominal Aortic balloon occlusion in placenta increta and/or percreta. The Journal of surgical research 2018, 222:75-84.

15. Xie L, Wang Y, Luo F-Y, Man Y-C, Zhao X-L: Prophylactic use of an infrarenal abdominal aorta balloon catheter in pregnancies complicated by placenta accreta. Journal of obstetrics and gynaecology: the journal of the Institute of Obstetrics and Gynaecology 2017, 37:557-561.

16. Cousins C: Medical radiation and pregnancy. Health physics 2008, 95:551-553.

17. Murji A, Crosier R, Rasuli P: Non-obstetric diagnostic imaging in pregnancy. CMAJ: Canadian Medical Association journal = journal de l'Association medicale canadienne 2015, 187:1309.

18. Masselli G, Brunelli R, Casciani E, Polettini E, Piccioni MG, Anceschi M, Gualdi G: Magnetic resonance imaging in the evaluation of placental adhesive disorders: correlation with color Doppler ultrasound. European radiology 2008, 18:1292-1299.

19. Zhu L, Xie L: Value of ultrasound scoring system for assessing risk of pernicious placenta previa with accreta spectrum disorders and poor pregnancy outcomes. Journal of medical ultrasonics (2001) 2019, 46:481-487.

20. Panici PB, Anceschi M, Borgia ML, Bresadola L, Masselli G, Parasassi T, Perrone G, Brunelli R: Intraoperative aorta balloon occlusion: fertility preservation in patients with placenta previa accreta/increta. The journal of maternal-fetal \& neonatal medicine: the official journal of the European Association of Perinatal Medicine, the Federation of Asia and Oceania Perinatal Societies, the International Society of Perinatal Obstetricians 2012, 25:25122516.

21. Collins SL, Ashcroft A, Braun T, Calda P, Langhoff-Roos J, Morel O, Stefanovic V, Tutschek B, Chantraine F: Proposal for standardized ultrasound descriptors of abnormally invasive placenta (AIP). Ultrasound in obstetrics \& gynecology: the official journal of the International Society of Ultrasound in Obstetrics and Gynecology 2016, 47:271275.

22. Tobias Angstmann, Gregory Gard, Tim Harrington, Elizabeth Ward, Amanda Thomson, Warwick Giles: Surgical management of placenta accreta: a cohort series and suggested approach:2010 Jan;202(1):38.

23. Broekman EA, Versteeg H, Vos LD, Dijksterhuis MG, Papatsonis DN: Temporary balloon occlusion of the internal iliac arteries to prevent massive hemorrhage during cesarean delivery among patients with placenta previa. 
24. Li K, Zou Y, Sun J, Wen H: Prophylactic balloon occlusion of internal iliac arteries, common iliac arteries and infrarenal abdominal aorta in pregnancies complicated by placenta accreta: a retrospective cohort study. European radiology 2018, 28:4959-4967.

25. Tokue H, Tokue A, Tsushima Y, Kameda T: Safety and Efficacy of Aortic Vs Internal Iliac Balloon Occlusion for Cesarean Delivery in Coexisting Placenta Accreta and Placenta Previa. Cardiovascular and interventional radiology 2020, 43:1277-1284.

26. Luo F, Xie L, Xie P, Liu S, Zhu Y: Intraoperative aortic balloon occlusion in patients with placenta previa and/or placenta accreta: a retrospective study. Taiwanese journal of obstetrics \& gynecology 2017, 56:147-152.

27. Dilauro MD, Dason S, Athreya S: Prophylactic balloon occlusion of internal iliac arteries in women with placenta accreta: literature review and analysis. Clinical radiology 2012, 67:515-520.

\section{Tables}

Table1. Placenta accreta scoring system[9]

\begin{tabular}{llll}
\hline & 0 & 1 & 2 \\
\hline Position of the placenta & Normal & Marginal placental previa or low & Completely placental previa \\
lying placenta & \\
Thickness of the placenta & $<3 \mathrm{~cm}$ & $3-5 \mathrm{~cm}$ & $>5 \mathrm{~cm}$ \\
Continuity of the clear space & Continuity & Local interruption & Disappeared \\
Bladder line & Continuity & Local interruption & Disappeared \\
Lacuna & None & Present & Fused with boiling water sign \\
Condition of the & Normal & The blood flow increased, forming & The emergence of "cross-border" \\
subplacental vascularity & blood flow & a cluster & blood vessels \\
Blood sinus of cervix & None & Present & Fused with boiling water sign \\
Morphology of cervix & Complete & Incomplete & Disappeared \\
History of cesarean section & None & 1 time & $\geq 2$ times \\
\hline
\end{tabular}

Table 2. General information of patients in three groups. 


\begin{tabular}{lllll}
\hline & $\square(\mathrm{n}=7)$ & $\square \mathrm{n}=88 \square$ & $\square \mathrm{n}=53 \square$ & P value \\
\hline Gestational age (weeks ) & $37.3 \pm 1.1$ & $36.4 \pm 1.5$ & $35.8 \pm 1.8 \# \&$ & 0.025 \\
Age & $30.6 \pm 5.3$ & $33.1 \pm 4.0$ & $32.8 \pm 3.5$ & 0.258 \\
BMI & $27.1 \pm 2.6$ & $27.1 \pm 3.0$ & $27.0 \pm 3.4$ & 0.962 \\
Prior cesarean & $0.6 \pm 0.5$ & $0.8 \pm 0.6$ & $1.2 \pm 0.6 \# \&$ & $<0.001$ \\
Curettage (n) & $1.3 \pm 3.0$ & $1.8 \pm 1.4$ & $2.0 \pm 1.7$ & 0.648 \\
Parity (n) & $3.0 \pm 3.2$ & $3.7 \pm 1.6$ & $4.2 \pm 1.9$ & 0.118 \\
Score & $3.6 \pm 0.5$ & $6.7 \pm 1.2 *$ & $11.2 \pm 1.1 \# \&$ & $<0.001$ \\
\hline
\end{tabular}

BMI, body mass index.

One-way analysis of variance and post hoc LSD analysis: *-Comparison between group $\square$ and group $\square$, P $\square 0.05$; \#Comparison between group $\square$ and group $\square, \mathrm{P} \square 0.05$; \&- Comparison between group $\square$ and group $\square, \mathrm{P} \square 0.05$.

Table 3. Intraoperative and postoperative data in the three groups.

\begin{tabular}{|c|c|c|c|c|}
\hline & $\square(n=7)$ & 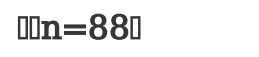 & 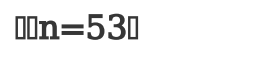 & $P$ value \\
\hline Total Hysterectomies & 0 & $2(2.27 \%)$ & $2(3.77 \%)$ & 0.697 \\
\hline Admission to ICU & 0 & $3(3.41 \%)$ & $1(1.89 \%)$ & 1.000 \\
\hline Transfused patients & $1(14.29 \%)$ & $14(15.91 \%)$ & $25(47.17 \%)$ & $<0.001$ \\
\hline Estimated blood loss (mL) & $514 \pm 212$ & $695 \pm 585$ & $1266 \pm 826 \# \&$ & $<0.001$ \\
\hline Median & 500 & 550 & 1000 & \\
\hline Percentiles (25-75) & $(300,600)$ & $(425,875)$ & $(700,1500)$ & \\
\hline Packed red blood cells (mL) & $86 \pm 227$ & $134 \pm 410$ & $323 \pm 418 \&$ & 0.023 \\
\hline Median & 0 & 0 & 0 & \\
\hline Percentiles (25-75) & $(0,0)$ & $(0,0)$ & $(0,600)$ & \\
\hline Postoperative estimated blood loss(ml) & $21 \pm 57$ & $17 \pm 45$ & $88 \pm 150 \# \&$ & $<0.001$ \\
\hline Postoperative transfused patients & 0 & $10(11.36 \%)$ & 18(33.96\%) & 0.002 \\
\hline Postoperative blood transfusion volume(ml) & $0 \pm 0$ & $45 \pm 140$ & $153 \pm 236 \# \&$ & 0.002 \\
\hline Median & 0 & 0 & 0 & \\
\hline Percentiles (25-75) & $(0,0)$ & $(0,0)$ & $(0,400)$ & \\
\hline Postoperative days & $4.3 \pm 1.0$ & $5.9 \pm 2.6$ & $7.8 \pm 4.7 \# \&$ & 0.002 \\
\hline Median & 4 & 5 & 6 & \\
\hline Percentiles & $(3,5)$ & $(4,7)$ & $(5,8.5)$ & \\
\hline Operation time (min) & $54.4 \pm 19.3$ & $65.5 \pm 29.7$ & $96.3 \pm 33.3 \# \&$ & $<0.001$ \\
\hline Fetal childbirth time(min) & $5.3 \pm 1.8$ & $5.4 \pm 2.2$ & $5.2 \pm 2.6$ & 0.877 \\
\hline Neonatal weight(g) & $3030.7 \pm 152.6$ & $2882.6 \pm 477.4$ & $2784.6 \pm 383.1$ & 0.242 \\
\hline Apgar(1min) & $9.3 \pm 1.3$ & $9.0 \pm 0.9$ & $8.4 \pm 1.1 \# \&$ & 0.001 \\
\hline Apgar(5min) & $9.7 \pm 0.8$ & $9.9 \pm 0.4$ & $9.7 \pm 0.7 \&$ & 0.066 \\
\hline
\end{tabular}

ICU, intensive care unit. 
One-way analysis of variance and post hoc LSD analysis: *-Comparison between group $\square$ and group $\square$, P $\square 0.05$; \#Comparison between group $\square$ and group $\square$, P $₫ 0.05$; \&- Comparison between group $\square$ and group $\square$, P匹0.05.

Table 4. Intraoperative and postoperative data about the placement of the balloon in the three groups. 


\begin{tabular}{|c|c|c|c|c|c|c|c|}
\hline & \multirow{2}{*}{$\begin{array}{l}\mathrm{a}(\mathrm{n}=7) \\
\mathrm{NIABO}(\mathrm{n}=7)\end{array}$} & \multicolumn{2}{|c|}{ प्य $\mathrm{n}=88 \square$} & \multirow[t]{2}{*}{$P$ value } & \multicolumn{2}{|c|}{ प्n=53ロ } & \multirow{2}{*}{$\begin{array}{l}P \\
\text { value }\end{array}$} \\
\hline & & $\operatorname{IABO}(\mathrm{n}=17)$ & $\operatorname{NIABO}(\mathrm{n}=71)$ & & $\operatorname{IABO}(\mathrm{n}=40)$ & $\operatorname{NIABO}(\mathrm{n}=13)$ & \\
\hline Total & 0 & $0(0.0 \%)$ & $2(2.8 \%)$ & 1.000 & $0(0 \%)$ & $2(15.4 \%)$ & 0.011 \\
\hline \multicolumn{8}{|l|}{ Hysterectomies } \\
\hline Admission to & 0 & $0(0.0 \%)$ & $3(4.2 \%)$ & 1.000 & $0(0 \%)$ & $1(7.7 \%)$ & 0.245 \\
\hline \multicolumn{8}{|l|}{ ICU } \\
\hline $\begin{array}{l}\text { Transfused } \\
\text { patients }\end{array}$ & $1(14.29 \%)$ & $1(5.9 \%)$ & $13(18.3 \%)$ & 0.288 & $14(35.0 \%)$ & $11(84.6 \%)$ & 0.002 \\
\hline Estimated & $514 \pm 212$ & $629 \pm 214$ & $758 \pm 749$ & 0.488 & $950 \pm 390$ & $2238 \pm 1052$ & $\square 0.001$ \\
\hline \multicolumn{8}{|l|}{ blood loss (mL) } \\
\hline Median & 500 & 600 & 500 & & 900 & 2000 & \\
\hline Percentiles & $(300,600)$ & $(500,750)$ & $(400,900)$ & & $(600,1200)$ & $(1500,2650)$ & \\
\hline$(25-75)$ & & & & & & & \\
\hline Packed red & $86 \pm 227$ & $47 \pm 194$ & $154 \pm 445$ & 0.336 & $213 \pm 311$ & $662 \pm 528$ & $\square 0.001$ \\
\hline $\begin{array}{l}\text { blood cells } \\
(\mathrm{mL})\end{array}$ & & & & & & & \\
\hline Median & 0 & 0 & 0 & & 0 & 400 & \\
\hline Percentiles & $(0,0)$ & $(0,0)$ & $(0,0)$ & & $(0,400)$ & $(350,1000)$ & \\
\hline$(25-75)$ & & & & & & & \\
\hline $\begin{array}{l}\text { Postoperative } \\
\text { estimated }\end{array}$ & $21 \pm 57$ & $23 \pm 47$ & $16 \pm 44$ & 0.556 & $69 \pm 118$ & $147 \pm 218$ & 0.102 \\
\hline blood loss(ml) & & & & & & & \\
\hline $\begin{array}{l}\text { Postoperative } \\
\text { transfused } \\
\text { patients }\end{array}$ & 0 & $1(5.9 \%)$ & $9(12.7 \%)$ & 0.679 & $11(27.5 \%)$ & $7(53.8 \%)$ & 0.101 \\
\hline Postoperative & $0 \pm 0$ & $18 \pm 73$ & $52 \pm 151$ & 0.364 & $105 \pm 181$ & $300 \pm 321$ & 0.008 \\
\hline $\begin{array}{l}\text { blood } \\
\text { transfusion } \\
\text { volume(ml) }\end{array}$ & & & & & & & \\
\hline $\begin{array}{l}\text { Postoperative } \\
\text { days }\end{array}$ & $4.3 \pm 1.1$ & $6.5 \pm 3.2$ & $5.7 \pm 2.5$ & 0.300 & $7.5 \pm 5.0$ & $8.9 \pm 3.5$ & 0.366 \\
\hline Median & 4 & 6 & 5 & & 6 & 8 & \\
\hline Percentiles & $(3,5)$ & $(4,7)$ & $(4,7)$ & & $(5,7.75)$ & $(6.5,10)$ & \\
\hline $\begin{array}{l}\text { Operation time } \\
(\min )\end{array}$ & $54.4 \pm 19.3$ & $81.4 \pm 19.5$ & $61.7 \pm 30.6$ & 0.013 & $90.0 \pm 25.9$ & $115.9 \pm 45.3$ & 0.013 \\
\hline Fetal childbirth & $5.3 \pm 1.8$ & $5.1 \pm 2.6$ & $5.5 \pm 2.1$ & 0.488 & $5.0 \pm 2.3$ & $5.7 \pm 3.5$ & 0.427 \\
\hline
\end{tabular}


time(min)

\begin{tabular}{llllllll} 
Neonatal & $3030.7 \pm 152.6$ & $2780.6 \pm 435.0$ & $2907.0 \pm 486.7$ & 0.330 & $2792.6 \pm 399.2$ & $2760.0 \pm 342.5$ & 0.793 \\
weight(g) & & & & & & & \\
Apgar $(1 \mathrm{~min})$ & $9.3 \pm 1.3$ & $8.8 \pm 0.8$ & $9.1 \pm 0.9$ & 0.192 & $8.4 \pm 1.0$ & $8.5 \pm 1.3$ & 0.641 \\
Apgar $(5 \mathrm{~min})$ & $9.7 \pm 0.8$ & $9.8 \pm 0.4$ & $9.9 \pm 0.4$ & 0.580 & $9.7 \pm 0.7$ & $9.7 \pm 0.6$ & 0.840 \\
\hline
\end{tabular}

IABO, Intra Abdominal Balloon Occlusion; NIABO, None Intra Abdominal Balloon Occlusion; ICU, intensive care unit.

\section{Figures}

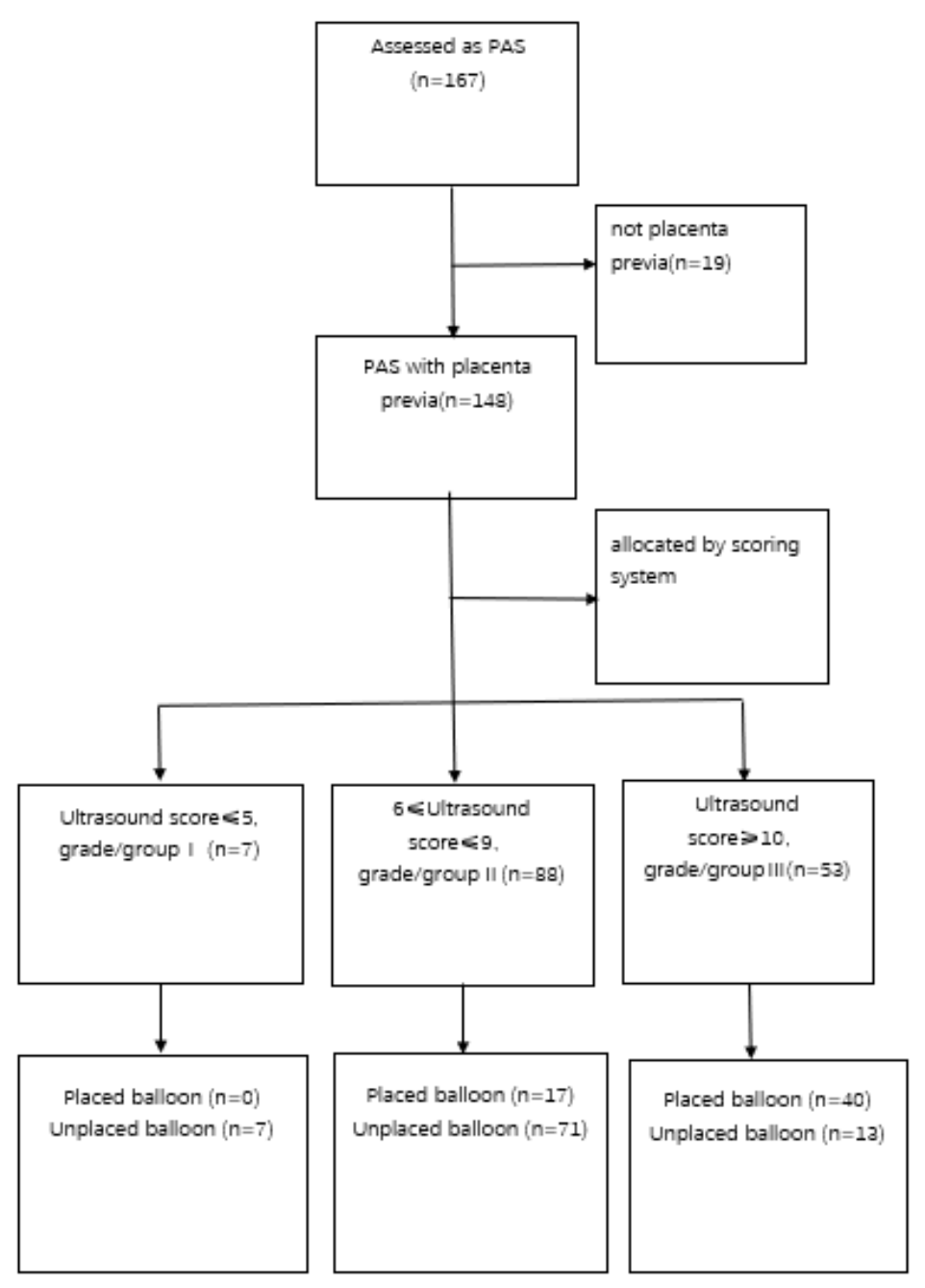

Figure 1

Flow of participants through the study. 